References:

1.MacKinnon A C, Liu X, Hadoke P W, et al. Inhibition of galectin-3 reduces atherosclerosis in apolipoprotein

E-deficient mice [J]. Glycobiology, 2013, 23(6): 654-663.

2.Yang Z, Liu Y, Deng W, et al. Hesperetin attenuates mitochondria-dependent apoptosis in lipopolysaccharideinducedH9C2 cardiomyocytes [J]. Mol Med Rep, 2014,9(5): 1941-1946.

3.Wu J J, Cui Y, Yang Y S, et al. Mild mitochondrial depolarization is involved in a neuroprotective mechanism of Citrus sunki peel extract [J]. Phytother Res,2013, 27(4): 564-571.

UDC 615.451:612.014 DOI 10.22448/AMJ.2017.3.101-102

\title{
ANTIOXIDANT PROPERTIES OF CONVOLVULUS ARVENSIS IN ADAPTATION OF ORGANISM TO COLD
}

\author{
E.Yu. Yurtaeva, V.A. Dorovskikh, N.V. Simonova, R.A. Anokhina, M.A. Shtarberg
}

Amur State Medical Academy, Blagoveshchensk, Russia

Summary. Numerous studies conducted in recent years, it is shown that the mechanism of the effect of environmental factors on a living organism, in particular, with the adaptation of warm-blooded organism to cold, there is a common pathogenetic link - excess production of free radicals. Perspective is an experimental study on the use of natural antioxidants derived from medicinal plants of the Amur region. In experimental conditions the possibility to correct free radical lipid oxidation of rats' organism membranes was studied with the oral introduction of the tincture of herb convolvulus that contains the complex of natural antioxidants. The application of the mentioned tincture in the conditions of oxidative stress induced by the influence of cold leads to the stabilization of the processes of peroxidation against the increase of antioxidant system activity.

Key words: the tincture of herb convolvulus, cold, oxidative stress, biological membranes lipid peroxidation, antioxidant system.

In recent years intensively studied the issues of increasing resistance of the organism to a state of hypoxia, which in one way or another initiates the development of many diseases and accompanies them, as well as develops as a result of influence on an organism of various extreme factors. Out our earlier studies have shown that exposure to low temperatures on warm-blooded organism increases the rate of tissue consumption of oxygen, necessary for energy supply, the increased heat production that is the cause of development of hypoxia, stimulating the generation of reactive oxygen species, initiating the peroxidation of lipids. In turn, the state of the adaptive-compensatory potential of the organism at the cellular level is determined by the capacity of antioxidant defense mechanisms. The extension of the range of disorders of free-radical origin in the conditions of cold exposure, leading to destruction of cells and determine the fate of organ, tissue and whole organism, requires the development of new highly effective antioxidants, specifically applicable to certain units of free-radical oxidation schemes and their rational use. Perspective in connection with the foregoing is an experimental justification for the use of natural antioxidants derived from medicinal plants of the Amur region, in particular on the basis of field bindweed (Convolvulus arvensis L.), since the availability of the resource base and the profitability of the technology of production emphasizes the economic efficiency of phytocorrection.

Materials and methods. In experimental conditions the possibility to correct free radical lipid oxidation of rats' organism membranes was studied with the oral introduction of the tincture of herb convolvulus that contains the complex of natural antioxidants. The animals were divided into 3 groups and each of them had 30 rats: intact animals which were held in standard conditions of vivarium; the control group in which rats were exposed to cold during three hours daily; the experimental group in which before cooling animals had a daily oral intake of the tincture in a dose of $5 \mathrm{ml} /$ $\mathrm{kg}$. It was found out that in the blood of experimental animals a daily cold exposure during three hours contributes to the increase of lipid hydroperoxides level (by $19-20 \%$ ), of diene conjugate (by $16-21 \%$ ), and of malonic dialdehyde (by $41-50 \%$ ) against the decrease of antioxidant system activity in the blood of intact animals. The introduction of the tincture to rats in the conditions of oxidative stress contributes to the reliable decrease in the blood of lipid hydroperoxides by $9-16 \%$, of diene conjugates by $8-17 \%$, malonic dialdehyde by $21-28 \%$ in comparison with the rats of the control group. While analyzing the effect of the tincture on the activity of the components of antioxidant system it was shown that the level of ceruloplasmin in the blood of animals was reliably higher by $10-26 \%$, of vita$\min \mathrm{E}$ by $18-23 \%$, of catalase by $10-28 \%$ in comparison with the same parameters of the rats of the control group.

So, the application of the mentioned tincture in the conditions of oxidative stress induced by the influence of cold leads to the stabilization of the processes of peroxidation against the increase of antioxidant system activity.

\section{REFERENCES}

Dorovskikh V.A., Borodin E.A., Lee O.N., Simonova N.V., Starberg M.A., Dorovskikh Yu.V. Comparative efficiency of different antioxidants during cold exposure and overheating. Blagoveshchensk; 2016 (in russian).

Dorovskikh V.A., Borodin E.A., Shtarberg M.A., Shtarberg S.A., Egorov K.E. Phospholipids as antiatherosclerotic drugs. In book: Lipoproteins and atherosclerosis. Abstracts of the Symposium devoted to the 110 anniversary from the birthday of academician N.N. Anichkov «Lipoproteins and atherosclerosis». Moscow; 1995: 41-46 (in russian). 
Dorovskikh V.A., Tseluyko S.S., Simonova N.V., Anokhina R.A. In the world of antioxidants. Blagoveshchensk, 2012 (in russian).

Landyshev Ju.S., Dorovskikh V.A., Tseluyko S.S., Lazutkina E.L., Tkacheva S.I., Chaplenko T.N. Bronchial asthma. Blagoveshchensk, 2010 (in russian).

Landyshev Ju.S., Dorovskikh V.A., Chaplenko T.N. Drug Allergy. St-Petersburg, 2010 (in russian).

Simonova I.V., Dorovskikh V.A., Simonova N.V., Shtarberg M.A. Non-specific preventive measures against respiratory diseases of nursery age children. Far Eastern Medical Journal 2009; 3:56-58 (in russian).

Simonova N.V. Herb extracts and oxidative stress in the ultraviolet irradiation conditions. Agricultural research Journal 2011; 8:23-26 (in russian).

Simonova N.V., Dorovskikh V.A., Anokhina R.A. Medicinal plants of the Amur region. Blagoveshchensk; 2016 (in russian).

Simonova N.V., Dorovskikh V.A., Shtarberg M.A. Effect of adaptogens of plant origin on the intensity of the processes of peroxidation of lipids of membranes under conditions of ultraviolet irradiation. Far Eastern Medical Journal 2010; 2:112-115 (in russian).

Simonova N.V., Dorovskikh V.A., Simonova N.P. Ultraviolet radiation and oxidative stress. The possibility of phitocorrection. Blagoveshchensk, 2014 (in russian).

Simonova N.V., Dorovskikh V.A., Li O.N., Shtarberg M.A., Simonova N.P. Tincture of medicinal plants and oxidative stress in the conditions of cold influence. Bulletin physiology and pathology of respiration 2013; 48:76-80 (in russian).

Simonova N.V., Lachin A.P, Simonova N.P. Efficiency in correction phytopreparations of lipid peroxidation of biomembranes the background ultraviolet radiation. Vestnik Krasnoyarsk state agrarian University 2010; 5:95-98 (in russian).

Zenkov N.K., Kandalintseva N.V., Lankin V.Z., Men'shchikova E.B., Prosenko A.E. Phenolic Bioantioxidant. Novosibirsk: SB RAMS; 2003 (in russian).

\section{REVIEW OF ACUPUNCTURE TREATMENT FOR MENTAL RETARDATION}

\section{Zhang chun yan}

The second hospital affiliated to heilongjiang university of Chinese medicine Rehabilitation theory and practice, chinese

Backgroud:thereare no reliable estimates of acupuncture treatment for mental retardation.

Obiective:combine results across studies to estimate the acupuncture treatment for mental retardation among children under the age of 18.

Key words:acupuncture treatment, mental retardation、 Review

\section{Introduction}

Mental retardation (MR) refers to a group of onset before the age of 18 or hindered mental retardation syndrome characterized by mental retardation and social adaptation difficulties. Clinical stage of development skill damage as the main feature, including cognitive, language, motor and social skills such as different levels of retardation.Current treatment methods at home and abroad are mainly: (1) medical therapy, (2) education therapy, (3) exercise therapy, (4) music therapy, (5) game therapy, (6) comprehensive rehabilitation methods currently available for most mental retardation can not be the cause of treatment, only a portion of the genetic metabolic diseases such as phenylketonuria, galactosemia, congenital hypothyroidism can be treated for the cause psychosis, through alternative therapies, diet therapy, drug therapy or surgical treatment method is effective treatment.Currently for mental retardation in children and more integrated rehabilitation methods. In general, Western medicine treatment of children with MR only focus on education and training and behavior guidance, and can not completely change the symptom index MR children, do not fundamentally change the situation of MR children with brain pathology, so restored to its normal level. Over the past decade, many doctors of traditional Chinese medicine treatment for MR has been actively explore research, reported in the literature increasing.

\section{Methods}

\subsection{Head acupuncture}

Doctors Yuan divided children with mental retardation into two groups: the group of needle of scalp acupuncture complied with rehabilitation ; the other group of rehabilitation.Treatment period of 3 months,After three months, Children of scalp needle while rehabilitation group on mental age, social behavior had significant improvment compared with the group of children with rehabilitation after acupuncture,Studies have shown that after 3 months of treatment, the needle of scalp line combined with rehabilitation training to improve children's mental age, the social aspects of the more effective than acupuncture rehabilitation group.

Dr Lee applied methods of acupuncture treatment of children with mental retardation in children. Dr Lee acupunctured temporal, frontal, occipital three acupuncture needles, while in the following acupunctures: Baihui, hegu, wai guan, San yin jiao, Tai chong, The results showed that after six months of acupuncture and rehabilitation, children has improved significantly in language, cognitive and motor function in three areas.About 